\title{
DE LA RESONANCIA A LA METONIMIA. LA TEMPRANA TEORÍA DEL SENTIDO DE LACAN
}

\author{
FROM RESONANCE TO METONYMY. \\ LACAN'S EARLY THEORY OF MEANING
}

Agustín KRIPPER

CONICET - Universidad de Buenos Aires

agustinkripper@gmail.com

\begin{abstract}
Resumen: El presente trabajo se propone demostrar que en su texto: "La función y el campo del habla y del lenguaje en el psicoanálisis", Lacan elabora, a partir de la tradición estética de la antigua India, el concepto de resonancia, el cual sirve de base para una técnica psicoanalítica de la interpretación mediante la evocación del sentido. En este concepto se reconoce un antecedente directo, hasta ahora inadvertido por los comentadores, de la noción de metonimia, que es central en la posterior doctrina lacaniana del significante.
\end{abstract}

Palabras clave: Resonancia. Metonimia. Metáfora. Sentido. Lacan.

Abstract: This work aims to demonstrate that in his text: "The Function
and the Field of Speech and Language in Psychoanalysis", Lacan creates
the concept of resonance based on the aesthetic tradition of ancient India,
which serves as a basis for a psychoanalytic technique of interpretation
through the evocation of meaning. This concept is recognized as a direct
antecedent of the notion of metonymy which until now has gone unnoticed
by commentators that is central to the later Lacanian doctrine of the 
signifier.

Key Words: Resonance. Metonymy. Metaphor. Meaning. Lacan.

\section{INTRODUCCIÓN}

La doctrina del significante es sin duda una de las piedras de toque del psicoanálisis de Lacan. Pero Lacan no arribó a la homología entre el inconsciente y el lenguaje de un día para otro, sino sólo tras un largo proceso, una de cuyas paradas no ha sido objeto de mucha indagación, a saber, la noción de resonancia. La consideramos un elemento que es crucial para la temprana teoría del lenguaje de Lacan. La presente exposición pretende revisar la función de la resonancia en "La función y el campo del habla y del lenguaje en el psicoanálisis" (1953), con el fin de discernir cómo ella se articula con la evocación y la interpretación, y los problemas que plantea.

\section{UN PRECEDENTE: LA DEVELACIÓN DEL SENTIDO}

La primera elaboración de una teoría del lenguaje en la obra de Lacan puede encontrarse en la segunda sección de "Palabras sobre la causalidad psíquica" (1947), donde el fenómeno de la locura es unido indisociablemente al "problema de la significación para el ser [humano, en este momento] en general -esto es, del problema del lenguaje para el hombre-" (Lacan, 1966a: 166). Según Lacan, el lenguaje no debe entenderse como un sistema de signos correlativo al sistema de las realidades, sino como algo que

está atravesado de punta a punta por el problema de la verdad: sea que delate [trahisse] la verdad, en la medida en que él es una expresión de (a) su herencia orgánica en la fonología de la flatus vocis; (b) las "pasiones de su cuerpo" en el sentido cartesiano, es decir, de su alma, en los cambios de sus emociones; (c) y la cultura y la historia que constituyen su humanidad, en el sistema semántico que lo formó de niño; sea que manifieste esta verdad como una intención, al abrirla eternamente a la pregunta por cómo lo que expresa la mentira de su particularidad puede lograr 
formular la universalidad de su verdad (Lacan, 1966a: 166; nuestra la redonda).

En esta compleja cita, se ve que el lenguaje revela la verdad de dos formas diversas: puede "delatarla" -expresarla a su pesar, pasivamente, por su bagaje (orgánico, mental, cultural)-; o bien puede "manifestarla" como una intención -cosa que plantea un problema "hegeliano" que no trataremos: la reconciliación de lo universal (del lenguaje) y lo particular (del ser)-. Así, la función del lenguaje concierne a la verdad-que siempre es la del ser humano-, y Lacan agrega que dicha función debe entenderse, en sentido heideggeriano, como una revelación de la verdad. La verdad para Heidegger es alétheia, un desocultamiento a la vez que un ocultamiento (1927: §43-44). La ambigüedad de este (des-)ocultamiento es ostensible en la cita: hablar es revelar así.

Lacan profundiza la distinción anterior diciendo que "la palabra no es un signo, sino un punto nodal [noeud] de significación”. Si el signo no señala una realidad, se debe a que es un nudo o anudamiento (noeud) de sentidos. De este modo,

cuando digo la palabra "cortina" [rideau], por ejemplo, no es meramente para designar por convención un objeto cuyo uso puede variar de mil maneras dependiendo de las intenciones con las que lo perciba el artesano, el comerciante, el pintor o el psicólogo de la Gestalt -ya sea como trabajo, valor de cambio, fisionomía coloreada o estructura espacial-. Metafóricamente, es una cortina de humo; mediante un juego de palabras, es una corte inapelable o una cohorte inamistosa, y mi amigo Cortiñas, quien domina mejor que yo estos juegos glosolálicos. Por decreto, es el límite de mi dominio o, de vez en cuando, una pantalla para mi meditación en una habitación que comparto con alguien más. Por un milagro, es el espacio que se abre al infinito, lo desconocido en el umbral o la partida matutina del paseante solitario. Por aprensión, es el movimiento que delata la presencia de Agripina en el Consejo del Imperio Romano, o la mirada de la Sra. de Chasteller por la ventana mientras pasa Lucien 
Leuwen. Por error, es Polonio, a quien golpeo gritando: “QQué oigo? ¿Una rata?”. Como interjección, durante el entreacto del drama, es mi grito de impaciencia o el signo de mi aburrimiento: “iTelón!” [rideau]. Por último, es una imagen del sentido como tal, que para descubrirse debe ser develado (Lacan, 1966a: 166-167).

La función de la palabra de designar por convención un objeto (el signo referido a la realidad), es diferenciada otra vez de la función de revelar: ser la "imagen del sentido" -o, mejor dicho, la imagen de una serie de sentidos que desbordan el sentido común-. La palabra rideau (cortina) así no designa tal objeto, y, aunque lo hiciese, tal objeto de por sí tiene distintos usos que varían en función de la intención de cada sujeto. Pero, más importante, rideau es "una imagen del sentido", que sólo aparece ("se descubre") por diversas "develaciones": por una metáfora (no teorizada aún), por un juego de palabras (sin un estatus claro), por un decreto (un acto de habla acaso), por un milagro (un lugar de "proyección", a lo mejor de la nada), por aprensión y por error (el cliché de la cortina que se mueve) y por interjección (el pedido de levantar el telón). Esta clasificación -de un rigor similar al de la enciclopedia china que Borges menciona en El idioma analítico de John Wilkins- es bastante caótica, y quizá por este motivo suele pasársela por alto. El argumento que propone es más simple que su orden: la función de la palabra no es la denotación de la cosa, sino el develamiento del sentido, un desocultar que oculta a la vez. Anticipándonos a lo que veremos, valdría decir que, en la palabra rideau, "resuenan" todos esos sentidos.

\section{EL CONCEPTO DE RESONANCIA}

Diezaños después, con "La función y el campo del habla y del lenguaje en el psicoanálisis", Lacan culminó su primera teoría del símbolo, el habla o palabra (parole), y el lenguaje. Si estas nociones fueron eclipsadas por la doctrina del significante, la resonancia, en cuanto concepto de su primera teoría, lo fue más aún. En efecto, la resonancia no es sólo un giro, sino un concepto, uno forjado en gran medida a partir de la antigua estética hindú. Que ella es un concepto se ve en dos puntos: por un lado, Lacan la emplea para pensar los usos y efectos del lenguaje mismo en la teoría y la práctica 
psicoanalíticas. Así, por conservar los términos freudianos la ambigüedad de la lengua, dice, "sus resonancias [hacen] incurrir en malentendidos"; también se debe reivindicar el término "verbalizar", "cuyas resonancias en francés evocan una figura de Pandora distinta que la de la caja (en la que tal vez habría que encerrar el término)" , ya que el sujeto "hace pasar [el acontecimiento] al Verbo, o, mejor dicho, al épos con el que en el presente cuenta los orígenes de su persona"; y además se ve que en el análisis la telepatía "es un caso de resonancia en las redes comunicantes del discurso (Lacan, 1966b: 239-240, 255 y 265). Por otro lado, la tercera y última sección del texto lleva por título: "Las resonancias de la interpretación y el tiempo del sujeto en la experiencia psicoanalítica".

Pero sobre todo la resonancia es, como veremos, un concepto que cimienta la interpretación:

el analista puede explotar el poder de los símbolos al evocarlos calculadamente en las resonancias semánticas de sus comentarios. Por este camino es seguro que un regreso al uso de los efectos simbólicos podrá avanzar hacia una técnica renovada de la interpretación (Lacan, 1966b: 294; nuestro subrayado).

Para precisar en qué consiste este proceso de la evocación, Lacan menciona un concepto de la tradición estética hindú: la dhvani, que consiste en "la propiedad del habla mediante la cual hace escuchar lo que no dice" (Lacan, 1966b: 295). Tan importante es esta tradición que Lacan apela a ella tres veces en el texto. Dichas referencias son: 1) un relato que ilustra la dhvani; 2) el sentido del enunciado determinativo: "una aldea sobre el Ganges"; y 3) un parágrafo del Gran Upanisad del bosque, obra de la tradición védica. Pero, para entender correctamente estas referencias, antes debemos ofrecer los rudimentos de la estética hindú.

1. Para entender esta "resonancia", téngase en cuenta que en francés verbaliser (verbalizar) significa, en el derecho, multar (o denunciar) a alguien, pero también hablar de más o demasiado tiempo, y que Pandora, además de referirse a la mujer de la mitología griega, es un término familiar, ya un poco antiguo, para designar a la policía. 


\section{LOS TRES SENTIDOS DEL DECIR}

En "La función y el campo...", Lacan se apoya en el libro clásico de Kanti Chandra Pandey sobre estética hindú, Indian Aesthetics (1950), que recoge la enseñanza de Abhinavagupta, un maestro del siglo X a. C. de dicha tradición. Además, Lacan se apoya, sin citarlo (Miller: 1995), en un artículo del poeta René Daumal, "Les pouvoirs de la parole dans la poétique hindoue" (1972). Como hasta el momento no pudimos acceder a estas dos fuentes, las compensaremos con la presentación del filósofo Jitendranath Mohanty -especialista en fenomenología y filosofía de la antigua India- sobre la materia en su libro, Classical Indian Philosophy $(2000)^{2}$.

La noción de dhvani, también llamada vyanjanā, la "sugerencia", fue asunto de controversia en las teorías semánticas hindúes. Gran parte de las escuelas admitían para las palabras dos tipos de sentidos: el primario, vācyārtha, y el secundario, laksyārtha. En el primero, la relación entre la palabra y el sentido se llama abhidhā (p. ej., la palabra "vaca" denota una vaca). El sentido primario es el denotado. En el segundo, la relación entre la expresión y su sentido se llama laksana (p. ej., la frase "una aldea sobre el Ganges" significa la aldea a orillas del río Ganges) ${ }^{3}$. El sentido secundario es algo que, aunque no es la denotación, se relaciona con ella, como ocurre en la expresión "león entre los hombres", que quiere decir una persona que obviamente no es un león, sino que posee la fortaleza y el coraje de un león. En principio, sería el sentido metafórico.

Ahora bien, ciertos filósofos admitían un tercer sentido de las palabras y oraciones: vyangya. El proceso de expresarlo era la vyanjanā o dhvani: la "sugerencia". Así, el sentido poético no es el denotado ni el relacionado objetivamente con la denotación (el "metafórico"), sino:

lo que es sugerido pero no puede derivarse de la denotación [...]. Cuando un poeta escribe una oración, cada palabra de

2. Por desgracia, sufriremos la limitación propia de la bibliografía secundaria, dado que, según nuestro conocimiento, estos libros clásicos no están disponibles en ningún idioma que no sea el sánscrito. Allí Mohanty expone la dhvani, concepto crucial de la estética hindú que concierne al sentido de las palabras y las oraciones, y se vale de la obra de Ānandavardhana, Dhvanyāloka (un texto sánscrito del siglo IX d. C.), y de las obras de Abhinavagupta, Bhārati, sobre la obra de Bharata, Nātyaśāstra (siglos cuarto y quinto d. C.) y Locana, sobre el mismo Dhvanyāloka

3. Cf., más adelante, la exposición de este mismo ejemplo por parte de Lacan. 
la oración, al igual que la oración entera, tiene su sentido primario, pero eso no es lo que el poeta quiere expresar. Él quiere sugerir un sentido más profundo. El sentido primario es como una lámpara, que manifiesta el sentido poético. La palabra vyangya, que designa el sentido poético, quiere decir "lo que es manifestado". El sentido literal manifiesta este sentido poético, pero no lo designa. Ambos sentidos se experimentan simultáneamente. El sentido literal es aprehendido, el sentido poético es sugerido. El primero es fácilmente accesible para el lector [común], el segundo sólo lo es para el lector cultivado. Ambos, como la luz y la oscuridad, coexisten, como en el crespúsculo. El poeta deja el sentido sin manifestar; no es "dicho" o "denotado". El lector cultivado, con la sensibilidad apropiada, lo experimenta. El desocultamiento del sentido es la función del vyanjanā (Mohanty, 2000: 134; nuestra la redonda).

La función de la dhvani de desocultamiento del sentido - donde el sentido manifiesto coexiste con el no manifiesto- nos recuerda el papel revelador del lenguaje. Ānandavardhana, teórico de esta tradición, define el alma de la oración poética como la dhvani en sí misma. Ella es un rasgo irreductible de la poesía genial, comparable con la belleza grácil de una mujer, irreductible a los rasgos de las partes de su cuerpo, a la ausencia de defectos o a la presencia de adornos. Y si bien algunos sentidos sugeridos pueden ser transmitidos por el sentido primario, en última instancia el sentido sugerido supone "algo intransmisible por el sentido primario": "la dhvani es un 'fracaso logrado'. El lenguaje no consigue designarla, pero en la poesía genial este fracaso logra expresarla, o, mejor dicho, sugerirla a los lectores cultivados" (Mohanty, 2000: 134). Nótese al pasar, además, que la dhvani se caracteriza en términos similares a los que Lacan usa cuando dice que "todo acto fallido es un discurso logrado" (Lacan, 1966b: 258). 


\section{LA RESONANCIA EN LAS TRES REFERENCIAS HINDÚES}

Con estos elementos, podemos dirigirnos ahora a las tres referencias de Lacan a la tradición de la India.

1. Recordemos que, para Lacan, la resonancia es una propiedad fundamental del habla: hacer escuchar lo que no dice. Esto es enseñado por el siguiente relato clásico de dicha filosofía:

Una chica, dicen, espera a su amante a la orilla de un río, cuando ve llegar a un brahmán. Ella se le acerca y exclama con el tono más amable: "¿Qué día afortunado es hoy para usted! El perro cuyos ladridos solían asustarlo no estará más en esta ribera, porque acaba de ser devorado por un león que frecuenta los alrededores...". La ausencia del león, por lo tanto, puede tener tantos efectos como su salto -que, si estuviese presente, daría una vez sola, según el proverbio apreciado por Freud- (Lacan, 1966b: 294-295; nuestra la redonda).

El fragmento del león que devora el perro proviene de Dhvanyāloka, de Ānandavardhana. El relato en sí es muy conocido y anterior a la obra del hindú, e ilustra la estética de lo implícito. El sentido expreso del verso es evidentemente que, dado que el perro fue muerto, el ermitaño ahora puede andar libremente por la orilla. Pero el sentido implícito es justamente lo contrario: como ahora hay un león dando vueltas, el peligro es aún mayor. Se ve el efecto de Witz, de un ingenio casi chistoso, del sentido implícito. Pero no olvidemos que el sentido expreso y el implícito son funcionalmente inseparables, siendo que el implícito corresponde al sugerido por la dhvani (cf. Broido, 1988: 95-96). Que "la ausencia del león puede tener tantos efectos como su salto", como dice Lacan, significa que el león es tan peligroso cuando está presente como cuando es sugerido esto es, cuando, ausente en la realidad, se hace presente en su ausencia al ser evocado-. Otro nombre de esto sería la "eficacia simbólica", o sea, la articulación significativa de lo humano.

2. La segunda referencia, que ya fue adelantada por el propio Mohanty, surge a propósito de la espinosa expresión psicoanalítica 
"instinto de muerte":

La detención de tantos analistas ante la incompatibilidad aparente de estos términos [los de "instinto" y "muerte"] [...] manifiesta una inocencia dialéctica que probablemente quedaría desconcertada por el problema que se plantea clásicamente a la semántica en el enunciado determinativo, "una aldea sobre el Ganges", con el que la estética hindú ilustra la segunda forma de las resonancias del lenguaje (llamada Laksanalaksana). Hay que abordar la noción de instinto de muerte a partir de sus resonancias en lo que llamaremos la poética de la obra de Freud-camino principal para acceder a su sentido- (Lacan, 1966b: 317; nuestra la redonda).

Lo que Lacan llama la segunda forma de las resonancias del lenguaje (Laksanalaksana), es lo que Mohanty denomina laksanā, la remisión al sentido secundario o metafórico ${ }^{4}$. Que la aldea esté "sobre el río Ganges", no quiere decir que esté literalmente "encima del río", cosa obvia, sino "a la orilla del río". Se ve que no se trata de una dhvani (sugerencia), ya que ésta remite no al segundo sentido, sino al tercero. Por lo tanto, bajo el término "resonancia", Lacan parece subsumir tanto la laksanā (metáfora), que apunta al segundo sentido (proceso que, como vimos, de algún modo se apoya en la denotación), como la dhvani (sugerencia), que apunta al tercer sentido (proceso que, en última instancia, no puede derivarse de la denotación, si bien mantiene un lazo con ella).

Así, aunque es verdad que la distinción entre el segundo y el tercer sentido no es nítida en el texto de Lacan, es posible reconstruirla. El león ilustra la dhvani (que mienta el sentido sugerido) y la aldea ejemplifica la laksanā (que mienta sentido el metafórico). La sugerencia y la metáfora son las dos formas de resonancia para Lacan, y, cosa importante, la diferencia entre ambas en último análisis depende de su grado de apoyatura en el sentido primario. Advirtamos también que Lacan dice que el instinto de muerte debe abordarse desde sus resonancias en la poética de la obra

4. Laksanā significa marca, señal, signo, síntoma, definición, designación, nombre, significación secundaria, marca en el cuerpo e incluso signo u órgano de virilidad. Laksanālaksanā puede entenderse como "indicación indicativa" (Wilden, 1968: 152) 
freudiana: hay que "acceder a su sentido" -es decir, retornar a Freud implica una operación de lectura que se apoya no sólo en lo que su prosa dice, sino en lo que en ella resuena-.

3. La tercera referencia es la Gran Upanisad del bosque. Esta Upanisad (libro sagrado) es la más antigua y la más grande de la tradición védica, data del siglo VII a. C., y fue comentada por el filósofo Śankara en el siglo VIII d. C., según los eruditos. Lacan da fin a "La función y el campo..." parafraseando casi literalmente esta obra:

Cuando los Devas, los hombres, y los Asuras terminaban su noviciado con Prajapâti, como leemos en el primer Brāhmana [explicación] de la quinta lección de la Brihadāranyaka Upanisad [Gran Upanisad del bosque], le rogaron: "Háblanos".

"Da”, dijo Prajapâti, el dios del trueno. "¿Me han entendido?". Y los Devas respondieron: "Nos dijiste: Dāmyata, doméñense" - con lo que el texto sagrado quiere decir que los poderes de arriba son gobernados por la ley del habla-.

"Da”, dijo Prajapâti, el dios del trueno. "¿Me han entendido?". Y los hombres respondieron: "Nos dijiste: Datta, den" -con lo que el texto sagrado quiere decir que los hombres se reconocen entre sí mediante el don del habla-.

"Da", dijo Prajapâti, el dios del trueno. "¿Me han entendido?". Y los Asuras respondieron: "Nos dijiste: Dayadhvam, sean clementes" - con lo que el texto sagrado quiere decir que los poderes de abajo resuenan con la invocación del habla-.

Eso, continúa el texto, es lo que la voz divina hace escuchar en el trueno: Sumisión, don, clemencia. Da da da.

Porque Prajapâti responde a todos: "Me han entendido" (Lacan, 1966b: 322).

El fragmento corresponde en realidad al segundo Brāhmana, titulado: 
"Las tres virtudes", y no al primero, como afirma Lacan ${ }^{5}$. También es probable que él haya dado con el relato por medio de T. S. Eliot, quien lo retoma a su turno en la quinta parte de La tierra baldía, titulada "Lo que dijo el trueno". Esta referencia es más difícil de penetrar, ya que, a diferencia de las otras dos, no parece proceder del libro sobre estética hindú citado por Lacan, ni situarse en el debate sobre los sentidos del decir. Sin embargo, él la utiliza de forma tal que la vincula con aquella temática.

Creemos que el fragmento puede ser leído como un apólogo de la función de la interpretación analítica. Prajapâti, el Creador, dice " $D a$ ", y cada partícipe - los dioses de arriba, los hombres y los dioses de abajo"entiende" algo distinto (nótese que entendre es "entender" y "escuchar", ambigüedad semántica que se sostiene del hiato que hay ambas acciones). El Creador dice: " $D a$ ", y en cada uno resuena algo distinto, en la medida en que " $D a$ " es escuchado-entendido como una sílaba que sugiere una compleción que se plasma en tres formas diversas: "Dāmyata", "Datta" y "Dayadhvam". El Creador responde "Me han entendu", confirmando así lo que cada uno ha escuchado-entendido, a pesar de su diversidad -o, mejor dicho, gracias a ella misma-. En efecto, el sentido al que el Creador apunta no se da por denotación ni por metáfora, sino por sugerencia. De hecho, es su forma más pura: " $D a$ " no designa nada ni se apoya en nada, no tiene apoyatura de sentido alguno, simplemente sugiere. El efecto poético de esta sílaba, insensata in extremis, se encomienda a los lectores, y ellos "resuenan con la invocación del habla".

Creemos poder aislar en el apólogo dos momentos como dos tiempos de la interpretación. Vimos que, para Lacan, el analista tiene que "explotar el poder de los símbolos al evocarlos calculadamente en las resonancias semánticas de sus comentarios", lo cual conlleva un "uso de los efectos simbólicos" que propicia "una técnica renovada de la interpretación" (Lacan, 1966b: 294). Por lo tanto, lo que el analista hace al interpretar no consiste en dar sentido (denotar), sino en evocar símbolos (sugerir). En el primer momento, " $D a$ ", el comentario del Creador, resuena diferentemente en cada personaje como dhvani, sugerencia, a la que Lacan llama evocación de este modo: "la función del lenguaje no es informar, sino evocar" (Lacan, 1966b: 299) y lo que desde el punto de vista de la

5. Cf. la versión castellana (Anónimo, 2002: 431-434), con la que hemos cotejado la cita de Lacan. 142)

6. Notemos, asimismo, que dhvani quiere decir sonido, murmullo e incluso trueno (Wilden, 1968 : 
información es redundancia, desde el del habla es resonancia ${ }^{7}$.

El segundo momento, la respuesta del Creador, "Me han entendu", supone que "cuando la pregunta del sujeto cobra la forma de un habla verdadera, [los analistas] la sancionamos con nuestra respuesta", pues "el habla verdadera ya contiene su propia respuesta: nosotros tan sólo duplicamos su antífona con nuestro lay [...], no hacemos más que dar al habla del sujeto su puntuación dialéctica" (Lacan, 1966b: 310). Sancionar es lo que el Creador hace duplicando un verso con otro, es decir, puntuando lo que el sujeto dice. Para Lacan, no es que, con el " $D a$ ", el Creador "quiera decir" algo distinto a cada uno, sino que el "querer decir" queda suspendido de lo que resuena en ellos -no de lo que oyen ellos, sino de lo que se oye en ellos-.

En este sentido van las pocas indicaciones de Lacan en este texto sobre la interpretación: el analista "descifra a qué 'parte' de este discurso se confía el término significativo", "considera el relato de una historia cotidiana como un apólogo que dirige sus pocas palabras a buen entendedor, una larga prosopopeya como una interjección directa, y, al contrario, un simple lapsus como una declaración muy compleja, e incluso el suspiro de un silencio como el desarrollo lírico entero al que suple": "lo que da sentido al discurso del sujeto es una puntuación feliz" (Lacan, 1966b: 252). En el segundo momento, retorna la cuestión del dar sentido, pero en otro aspecto distinto del anterior. El dar sentido, propiamente, no da nada, ya que se ve reducido al mínimo acto de puntuar -una puntuación afortunada u oportuna-. Además, cuando el Creador puntúa "Me han entendido", no puede sonar, en este contexto, sino como la impostura del saber. Si la lectura de cada personaje es válida, es porque "lo que dijo el trueno" no quería decir nada. Así, vemos cómo Lacan reduce a un mínimo la via di porre, para reencaminar el análisis por la via di levare extremada (1986: 250). La interpretación no "da sentido" en ningún momento, pues la resonancia evoca sentido -arroja un decir cuyo sentido surge del analizado, no del analista- y la puntuación sanciona ese sentido -sancionando el texto que surge del analizado-. Agreguemos una dificultad: si bien parece que puntuar no es dar sentido, Lacan también afirma que la puntuación

7. Lacan precisa cómo opera la resonancia en la evocación de los símbolos. Éstos son primarios, pues "subyacen a todos los semantemas de una lengua"; por eso podemos "restituir al habla su pleno valor evocativo mediante una indagación discreta de las interferencias de ellos" (Lacan, 1953: 295). El carácter así llamado primario, sin embargo, no es aclarado del todo, y será reformulado en la doctrina del significante. 
"una vez puesta, fija el sentido; cambiarla lo renueva o lo trastorna; y la incorrecta lo distorsiona" (Lacan, 1966b: 313-314). Acaso esto podría explicarse diciendo que el sentido no es, estrictamente, "dado" en cuanto "proyectado" del analista al analizado, sino producido por una puntuación sobre un único texto: el discurso, la palabra, del analizado, lo cual no hace más que relanzar la resonancia. Según esto, la resonancia sería un nombre de lo que en el psicoanálisis se llama la asociación libre.

\section{LA RESONANCIA DE LO SIMBÓLICO}

Precisemos ahora la concepción del síntoma que Lacan propone con esto. Un síntoma posee al menos "la sobredeterminación de un doble sentido", "es un símbolo de un conflicto difunto más allá de su función en un conflicto presente no menos simbólico", y si el analista sigue

la ramificación ascendente del linaje simbólico en el texto de las asociaciones libres del paciente, a fin de ubicar los puntos nodales de su estructura en los lugares en los que sus formas verbales se cruzan [...] [entonces] los sintomas pueden resolverse totalmente en un análisis de lenguaje, porque un síntoma está en sí mismo estructurado como un lenguaje: un síntoma es un lenguaje cuya habla debe ser liberada (Lacan, 1966b: 269; nuestra la redonda).

Un anudamiento sería el meollo del síntoma, por cuya liberación pasa el hilo del análisis. Así, la interpretación sería un acto de liberación. Pero, ¿qué es esta estructura de lenguaje? Lacan define aquí el inconsciente como "esa parte del discurso concreto en cuanto transindividual de la que el sujeto no dispone para reestablecer la continuidad de su discurso consciente" (Lacan, 1966b: 258). La definición es freudiana, pues esa parte no disponible del discurso instaura una discontinuidad en la conciencia. Por eso el inconsciente es "el capítulo de mi historia que está marcado por un blanco u ocupado por una mentira: es el capítulo censurado", pero "la verdad puede ser reencontrada" y "casi siempre ya está escrita en otro lugar" (Lacan, 1966b: 259). Por obra de la represión la verdad está disponible para el sujeto en otra parte: en los monumentos (síntoma histérico estructurado como lenguaje), los documentos de archivo (recuerdos infantiles de origen 
desconocido), la evolución semántica (stock de palabras y acepciones de un vocabulario particular, y un estilo de vida y carácter), las tradiciones y leyendas (historia heroizada que se trasmite) y las huellas, que "se conservan en las distorsiones exigidas por la inserción del capítulo adulterado en los capítulos que lo enmarcan, capítulo cuyo sentido será reestablecido por mi exégesis" (Lacan, 1966b: 259). La interpretación restituye, por lo tanto, el sentido de todas estas formaciones.

Así, las producciones de la neurosis

son los elementos herméticos que nuestra exégesis resuelve, los equívocos que nuestra invocación disuelve, y los artificios que nuestra dialéctica absuelve, liberando el sentido aprisionado de modos que van desde revelar el palimpsesto hasta dar la solución del misterio y perdonar el habla (Lacan, 1966b: 281; nuestra la redonda).

La exégesis, la invocación y la dialéctica son, creemos, formas de nombrar la interpretación, ya que ella libera el sentido aprisionado de los siguientes modos: "revelar el palimpsesto" (traer a la luz, en el texto mismo, las huellas de una escritura anterior que fue borrada para escribir la que aparece más perceptible); "dar la solución" (donner le mot, literalmente "dar la palabra", dar la clave del misterio, deshacer el extrañamiento primario de la neurosis); y, en fin, "perdonar el habla" (pardonner la parole, acaso aceptar el hecho de que la palabra no puede decir, su límite). Además, "resolver", "disolver" y "absolver" retrotraen al latín solvere, liberar, soltar y también liberar un dinero, pagar, acepciones que parecen evocar la Aufhebung hegeliana, del verbo aufheben (cuyo heben sería paralelo al solvere), levantar, abolir, sublimar, cancelar, saldar una deuda, preservar e incluso trascender -asimismo Freud hablaba del "levantamiento" de las represiones, y notemos que la via di levare antes mencionada entraría en esta serie-. En la última cita, además, se ve de nuevo cómo Lacan produce en su escritura la misma resonancia de la que su discurso trata.

Esto conduce a Lacan a definir el síntoma como:

el significante de un significado que ha sido reprimido de la conciencia del sujeto. El síntoma, símbolo escrito en la arena de la carne y en el velo de Maya, participa 
del lenguaje mediante la ambigüedad semántica que subrayamos en su constitución. Pero es una palabra que se ejercita plenamente, ya que incluye el discurso del otro en el secreto de su cifra. Fue al descifrar esta palabra que Freud redescubrió el primer lenguaje de los símbolos, todavía vivo en los sufrimientos del hombre civilizado (Lacan, 1966b: 280-281; nuestra la redonda).

El síntoma es así el resultado de un proceso por el que se reprime un significado y en su lugar retorna un significante. Pero Lacan no es muy claro respecto de dicho proceso. Él afirma que la metáfora "es un sinónimo del desplazamiento simbólico puesto en juego en el síntoma”, pero al comparar el trabajo del sueño con una retórica, dice que tal retórica consiste en "la elipsis y el pleonasmo, el hipérbaton o la silepsis, la regresión, la repetición y la aposición -éstos son los desplazamientos sintácticos-; la metáfora, la catacresis, la antonomasia, la alegoría, la metonimia y la sinécdoque -éstas son las condensaciones semánticas-" (Lacan, 1966b: 260 y 268). Esto plantea un problema: Lacan caracteriza la metáfora como un desplazamiento simbólico, y unos renglones más adelante opone la metáfora y la metonimia, ambas en calidad de condensaciones, a los desplazamientos. Podríamos resolver esto, en parte, notando que la metáfora y la metonimia quedan del lado de la condensación porque ésta es justamente caracterizada como "semántica". Lo crucial sería a esta altura, para Lacan, que una y otra conciernen al campo de la semántica (o sea, del significado), no de la sintaxis (es decir, del significante). Aquí podemos ver cómo Lacan aún no termina de subordinar el significado al significante.

En este temprano modelo, la estructura de lenguaje del síntoma depende de su ambigüedad semántica, cuya polisemia, proveniente del discurso del otro, inconsciente, lo eleva al rango de palabra plena. Por eso el síntoma es descifrable como una palabra, esto es, como un hablar, en un proceso de liberación del sentido. De este modo, "hacer consciente lo consciente" es rebautizado por Lacan como "verbalizar" con el propósito de enterrar el "tomar conciencia" psicologista, por el cual el proceso analítico meramente "haría pasar" un contenido de un sitio, el inconsciente, a otro, la conciencia. En cambio, la verbalización no equivale a una acumulación de saber, sino a una reconfiguración de la relación con el saber, por así decirlo. 


\section{CONCLUSIONES: DESTINOS DE LA RESONANCIA Y DE LO SIMBÓLICO}

Para concluir, puede decirse que nuestro recorrido permitió revisar la primera concepción del lenguaje de Lacan en base a dos nociones: la puntuación y la sugerencia. Hemos mostrado que el uso que Lacan hace de la estética hindú, lejos de ser incidental, es sistemática, y que ésta permite formalizar una temprana teoría del lenguaje, hasta ahora inadvertida por los comentadores, que se articula por primera vez en "Palabras sobre la causalidad psíquica” y culmina en "La función y el campo...”. Así, mientras que el nudo de sentidos de 1947 se continúa en la puntuación de 1953, el develamiento de sentidos de los años cuarenta tiene su prosecución en lo que, según hemos procurado demostrar, Lacan forja no sólo como término, sino como concepto pocos años más tarde, a saber, la "resonancia" - $\sin$ duda, resonancia del sentido metafórico, pero, sobre todo, resonancia del sentido sugerido-. De este modo, la función de la palabra de desocultar ocultando de 1947 se prosigue en el hacer escuchar lo que ella no dice de 1953, lo cual acaso no da jamás con el fondo último de lo no dicho. Por otra parte, hemos expuesto el modo en el que la resonancia se articula en la noción de síntoma simbólico, así como las consecuencias técnicas que ello implica en cuanto a la técnica de la interpretación analítica.

Por último, propongamos una crítica de la distinción entre el sentido denotado, el metafórico y el sugerido. Si los contextos comprobados son los usos posibles del término admitidos por el momento histórico de una lengua dada, entonces puede decirse que el sentido metafórico no se deriva del sentido denotado (como afirma la estética hindú, para la cual lo originario sería la acepción de diccionario y lo derivado sus símiles semánticos), sino que, al revés, el sentido denotado es una metáfora muerta, cristalizada, resto de una metáfora viva. El problema residirá, a partir de entonces, en esclarecer la naturaleza de la operación metafórica, que sin lugar a dudas no consiste en una derivación semántica. Creemos encontrar una respuesta a esto en la definición que Lacan en 1957, en "La instancia de la letra..." (1966c), dará de la metáfora como sustitución de un significante por otro significante. La exploración del paso de la primera teoría del lenguaje de Lacan, aquí presentada, a su segunda teoría, de fines de los años cincuenta y conocida como la doctrina del significante, será 
objeto de futuras investigaciones ${ }^{8}$.

\section{REFERENCIAS BIBLIOGRÁFICAS}

ANÓNIMO (2002). Gran Upanisad del Bosque. Madrid: Trotta.

BROIDO, M. (1988). "Killing, Lying, Stealing, and Adultery: A Problem of Interpretation in the Tantras". En Buddhist Hermeneutics, D. S. López (ed.), 71-118. Honolulu: University of Hawaii Press.

DAUMAL, R. (1972). "Les pouvoirs de la parole dans la poétique hindoue”. En Essais et Notes, II (1935-1943): Les Pouvoirs de la Parole. París: Gallimard.

FREUD, S. (1986). "Sobre psicoterapia". En Obras completas, vol. VII, 247-57. Buenos Aires: Amorrortu.

HEIDEGGER, M. (1927). Sein und Zeit. Max Niemeyer: Tubinga. (2001). "Logos (Heráclito, fragmento 50)". En Artículos y conferencias. Barcelona: Ediciones del Serbal.

LACAN, J. (1966a). "Propos sur la causalité psychique". En Écrits, 151193. París: Le Seuil.

(1966b). "Fonction et champ de la parole et du langage en psychanalyse". En Écrits, 227-322. París: Le Seuil.

(1966c). "L'instance de la lettre dans l'inconscient ou la raison depuis Freud ". En Écrits, 493-528. París: Le Seuil.

MILLER, J.-A. (1995). "Petite introduction aux pouvoirs de la parole". La Lettre mensuelle 142, 21-23.

MOHANTY, J. (2000). Classical Indian Philosophy. Lanham: Rowman and Littlefield.

WILDEN, A. (1968). The Language of the Self: The Function of Language in Psychanalysis. Baltimore: The Johns Hopkins University Press.

Recibido el 14 de marzo de 2017.

Aceptado el 25 de mayo de 2017.

8. Simplemente adelantaremos dos hipótesis. Por un lado, la puntuación será reformulada en 1957

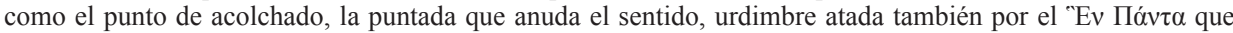
Heidegger reinserta en la función del Logos: la reunión de lo múltiple (Cf. Heidegger, 2001: 161-62). Por otro lado, no está claro si Lacan reformulará la resonancia en 1957 como la metáfora o la metonimia. Ya la relación entre ellas es compleja. Porque aunque parecen estar en pie de igualdad en "La instancia de la letra...", una lectura más detenida de este texto, que nos propondremos hacer en un próximo trabajo, demostraría que ya allí la metonimia es, de hecho, el fundamento de la metáfora. 
